\title{
DEVELOPMENT OF CODI (CO-DRUG INTERACTION) SOFTWARE AS DRUGS PRESCRIPTION ANALYSIS
}

\section{MUHAMAD RINALDHI TANDAH ${ }^{1 *}$, YUSRIADI ${ }^{1}$, ALWIYAH MUKADDAS ${ }^{1}$, KHUSNUL DIANA ${ }^{1}$, AHMAD ANGGARA SADEWA ${ }^{1}$}

\author{
${ }_{1}^{1}$ Pharmacy Department, Faculty of Mathematics and Natural Sciences, Tadulako University, Palu, Indonesia
} *Email: prof.aldhi@gmail.com

Received: 02 Sep 2020, Revised and Accepted: 09 Oct 2020

\section{ABSTRACT}

Objective: This study intends to design software algorithms, which is called Co-Drug Interaction (CODI), that able to analyse drug interactions in prescription and recommendations for further correction by replacing active substances based on the E-book Drug Interaction Facts and provide drug information features.

Methods: The research used data collection and conversed into programming languages. Java language programme choosed to build the entire application as its considerable free of charge and recognizable interface to use. The reference book is also used to help in prescribing and evaluating the reliability and efficiency of the software.

Result: The evaluations were performed by analyzing 30 groups of medicine based on 2 diseases, which are hypertension and diabetes mellitus.

Conclusion: The algorithm design and evaluation are in accordance with the planned output.

Keywords: Drug prescription, Drug interaction, System information, Java language programme

(C) 2021 The Authors. Published by Innovare Academic Sciences Pvt Ltd. This is an open access article under the CC BY license (http://creativecommons.org/licenses/by/4.0/) DOI: http://dx.doi.org/10.22159/ijap.2021.v13s2.04 Journal homepage: https://innovareacademics.in/journals/index.php/ijap

\section{INTRODUCTION}

Drug interactions and its side effects are still an ongoing problem, whether in the clinical or the community scope. This will be exacerbated by the use of more than 1 type of drug that will lead to undesirable polypharmacy prescription. It is known that the use of many drugs at one time has the potential for drug interactions. the role of pharmacists is needed to prevent this event from occurring as long as disease management is still using drugs [1, 2]. In a drug prescription, it is necessary to check drug interactions and requires knowledge regarding to the types of drug interactions that will need a lot of references. However, there a few pharmacies that do not have the books. For instance, the software is needed in pharmacist work place because it can combine information efficiently to check drug interactions. In recent time, a lot of software has been made, but to use the software is still using the internet which is less helpful in remote area where there is no insufficient infrastructure to delivering internet connection.

Utilization of technology and the internet at this time can no longer be stopped, including in the health sector. People have always had to go to the primary health care or clinic, even for minor symptoms. Maybe without realizing it, those situation sacrificed time, effort, and bill at an inconsiderable price. In emergency situations, especially for the elderly and children, must be addressed immediately before they have a worse impact. The use of information systems is expected to increase service efficiency without compromising patient safety [3]. In the pharmaceutical field, the software is widely used, for example, checking drug interactions (Medscape) from the https:// reference.medscape.com/drug interaction checker, (Uptodate) site from https://www.uptodate.com/, and others. Using the site as the source of information has its limitations to get internet access. Meanwhile, the UpToDate website can be accessible by paying an amount of fee, which it is not affordable for everyone.

This research aim is to develop a software called CODI (Co-Drug Interaction) to help analyze prescriptions received by patients and assist drug information services by offline and particularly built to give a hand to the pharmacist in the rural area. CODI (Co-Drug Interaction) is made with Java programming language which will be composed of several features, including features of drug interaction analysis, drug information features and recommendation features if there is an interaction in a prescription to analyze prescription drugs based on 2 disorder, which are hypertension and diabetes mellitus.

The diseases are choosen as its one of the most common diseases in Indonesia. Both of these diseases potentially using several drugs simultaneously and can point out to negative effect due to its interaction. According to Nurlaelah et al. (2015) [4], drug interactions in the treatment of type 2 diabetes mellitus with hypertension in the outpatient installation at Undata Hospital Palu stated that 52 patients experienced drug interactions with a general percentage of $85.2 \%$ and a percentage of drug interactions with pharmacokinetic mechanisms of $18.2 \%$, drug interactions with pharmacodynamics were $72.7 \%$, and drug interactions with unknown mechanisms were 9.1\%. Antihypertensive drug interactions in primary hypertensive patients at the Luwuk Hospital Outpatient Installation for the January-March 2016 period were $43.2 \%$ and the percentage of drug interactions with pharmacokinetic mechanisms was $10 \%$ and drug interactions with pharmacodynamics was $90 \%$ [5]. Description of potential drug interactions for diabetes mellitus in outpatient prescription drugs at Dr. Mintohardjo, from the results obtained by 310 prescription sheets, found that 204 prescription sheets (65.80\%) experienced potential drug interactions and more interactions were found on prescription sheets that received drugs $\geq 5$ kinds of drugs [7]. Based on the high rate of drug interactions in patients with hypertension and diabetes mellitus, it is necessary to create software to make it easier to analyze interactions on drug prescriptions in order to reduce the incidence of drug interactions that occur.

\section{MATERIALS AND METHODS}

\section{Materials and tools}

Laptop Lenovo Ideapad 330 with Intel® Celeron® N4000 CPU @ $1.10 \mathrm{GHz}$ (2 CPUs) (produced in Taiwan in 2018, bought in Indonesia at the same year), NetBeans IDE version 8.1 (released 16 November 2015 worldwide), Mouse Logitech M221 wireless, Wifi, e-book Drug Information Handbook 17th Edition, e-book Drug Interaction Facts 2009 e-book Top 300 Pharmacy Drug Cards, e-book British National Formulary $7^{\text {th }}$ Edition, e-book High Blood Pressure-Medicines to Help You, and e-book Indonesian Pharmacopoeia Edition V. 


\section{Data collection providing CODI (Co-drug interaction) software}

This software requires information on drug interactions and recommendations to manage its interactions, dosages, indications, contraindications, storage, and side effects. This information can be found in e-book Drug Information Handbook 17th edition, e-book Drug Interaction Facts 2009, e-book Indonesian Pharmacopoeia V Edition, e-book Top 300 Pharmacy Drug Cards, e-book British
National Formulary 74 ${ }^{\text {th }}$ Edition, and e-book High Blood PressureMedicines to Help You. All of this data is combined with programming commands for each feature.

Algorithm conversion to programming language providing CODI software

The algorithm conversion to programming language providing CODI (Co-Drug Interaction) software can be seen in fig. 1.

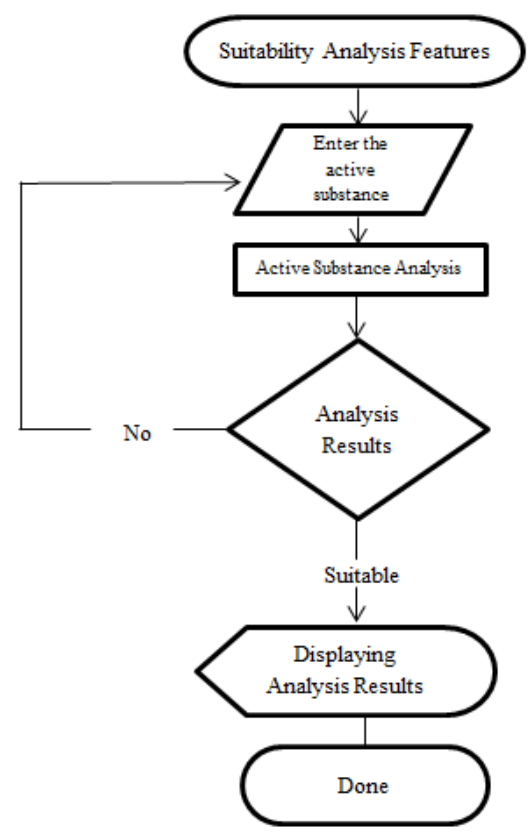

Fig. 1: Algorithm of suitability analysis features

In the suitability analysis feature, drug interaction information data is combined with commands that directly analyze whether there are drugs interacting based on drug interaction information data. In this feature, the form design (display) of this feature is made in the form of a list to select active substances (fig. 2).
The drug information feature contains dosage information, indications, contraindications, storage, and side effects based on 2 diseases, namely hypertension and diabetes mellitus. This information is taken from references mentioned earlier; then the data is combined with programming commands (fig. 3 ).

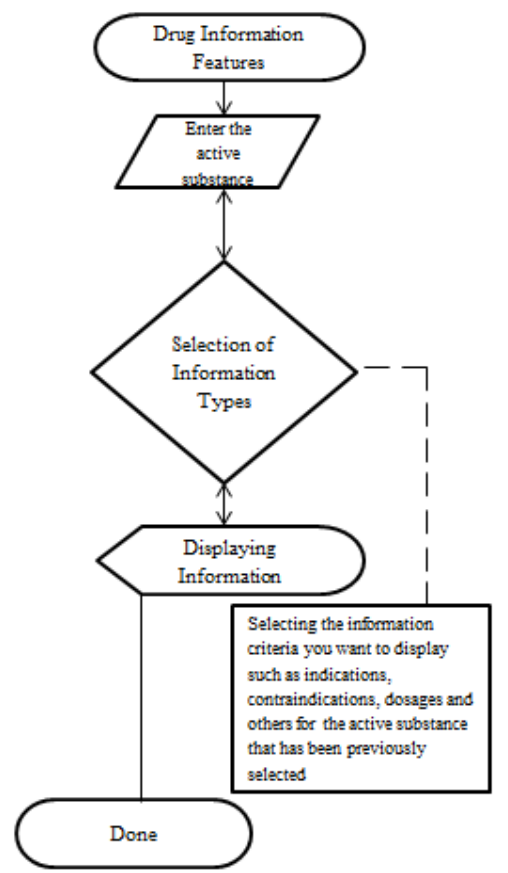

Fig. 2: Algorithm of drug information features 


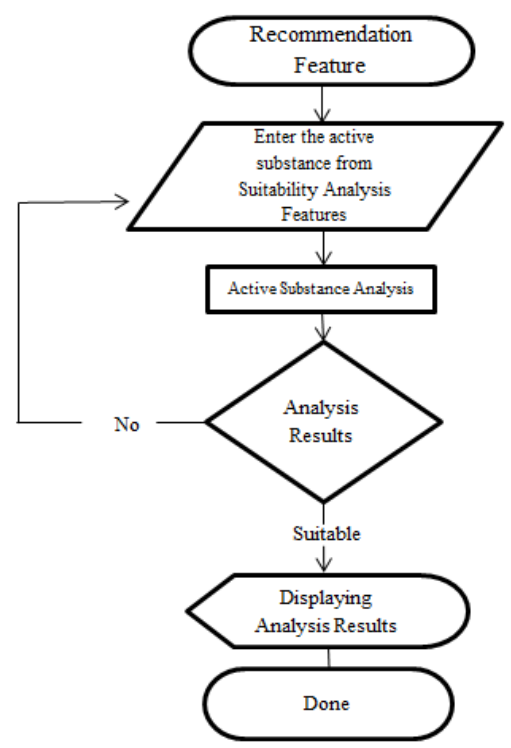

Fig. 3: Algorithm of recommendation feature

This recommendation feature uses data management which is combined with commands that directly provide management information when there is an interaction based on data management.

\section{Evaluation of CODI (Co-drug interaction) software}

Evaluation is carried out by looking at the variable aspects of software quality, but there are some aspects that are not tested because they are not included in the scope of the usefulness of the
CODI software, other than that, the evaluation is only strengthened in the simulation. Checking of active interacting substances and recommendations. The following is a table of the quality variables of the CODI software.

Prescription drug analysis with CODI (Co-drug interaction) software

The flowchart of the analysis of prescribing drugs with CODI software can be seen in fig. 4 .

\section{Table 1: Software quality variables}

\begin{tabular}{l} 
Sub variable \\
\hline Reliability (the ability of the software to \\
carry out its functions) \\
Efficiency (the computational resources \\
required by the software to perform its \\
functions)
\end{tabular}

\section{Indicator}

The active substance selection test was designed by designing 30 groups of active substances based on 2 diseases, namely hypertension and diabetes mellitus, listed in the Drug Interaction Facts.

The accuracy of the command form and the access button to the command by pressing each access button to the command and seeing the suitability of the command carried out by the CODI (Co-Drug Interaction) software. The efficiency evaluation sheet is included in the attachment.

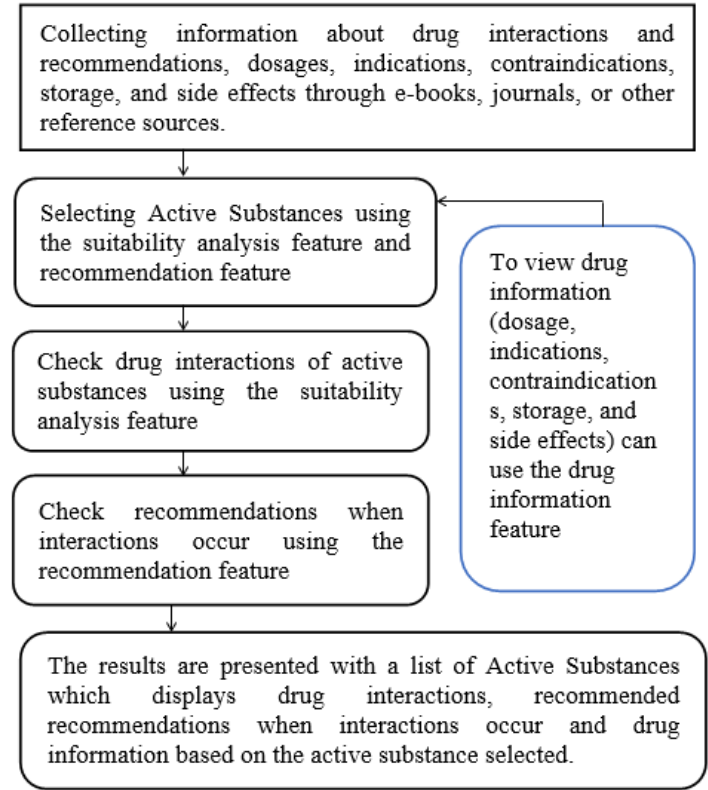

Fig. 4: Analysis of prescribing drugs with CODI software 


\section{RESULTS AND DISCUSSION}

\section{Making CODI (Co-drug interaction) software}

CODI (Co-Drug Interaction) software was created using the NetBeans IDE with the Java programming language. A programming language is the instructions understood by the computer to perform certain tasks. The Java language was developed at Sun Microsystems and was introduced to the public in 1995; just like C++, Java is also an object-oriented language; thus, Java also makes it easy to build large-scale applications. As a high-pitched language, which uses commands that are easily understood by people [6].

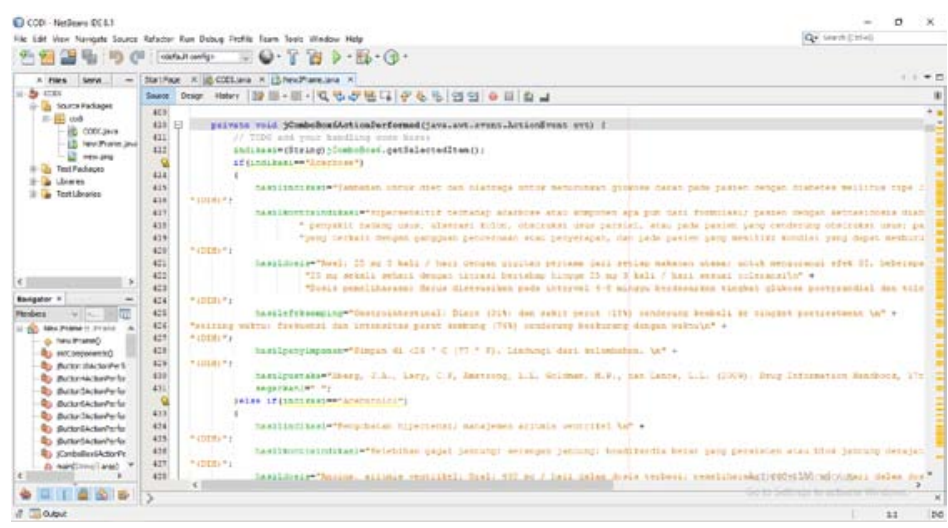

Fig. 5: Coding display following the algorithm design

In the coding process, the features are made according to the algorithm design (fig. 5). In the algorithm design, interaction checks and recommendations when interactions occur are described by selecting the active substance that you want to know first, then determining what information you want to know. The input of active substances that you want to know is five entries, which are the advantages of this software which aims to increase the active substance that you want to know the interaction and recommendations if there is an interaction when the active substances are used together, recommendation information if an interaction occurs is an advantage of this software because in general, other software rarely provides this information. The suitability analysis feature (fig. 6) and the recommendation feature have the same input because in this case, the active substance that you want to know is the same so that the input is made the same for ease of use.

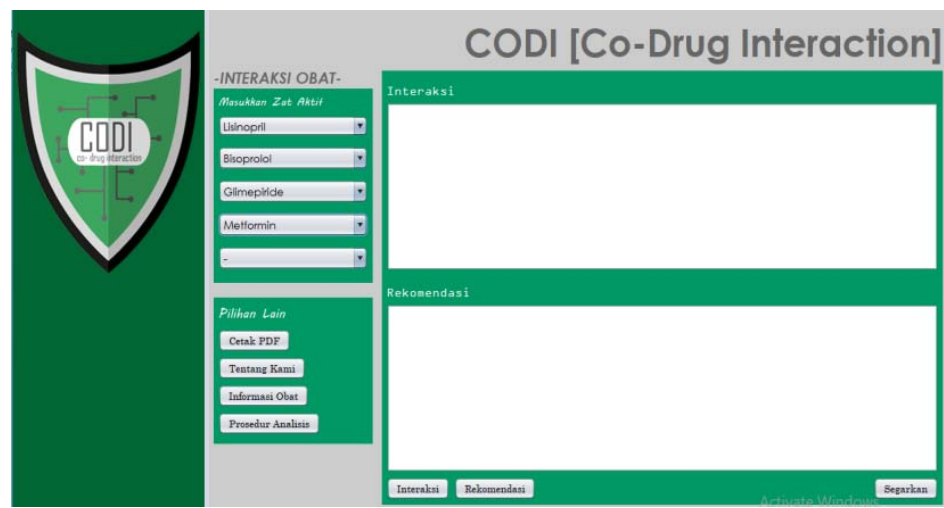

Fig. 6: Input on the suitability analysis feature and the recommendation feature

To check drug information, first pressing the drug information button then selecting the active substance you want to know, then determining what information you want to know, the available information includes indications, contraindications, dosage, side effects, and storage; the information results can be seen in fig. 7. All drug information provided is in Indonesian, making it easier to analyze drug prescriptions.

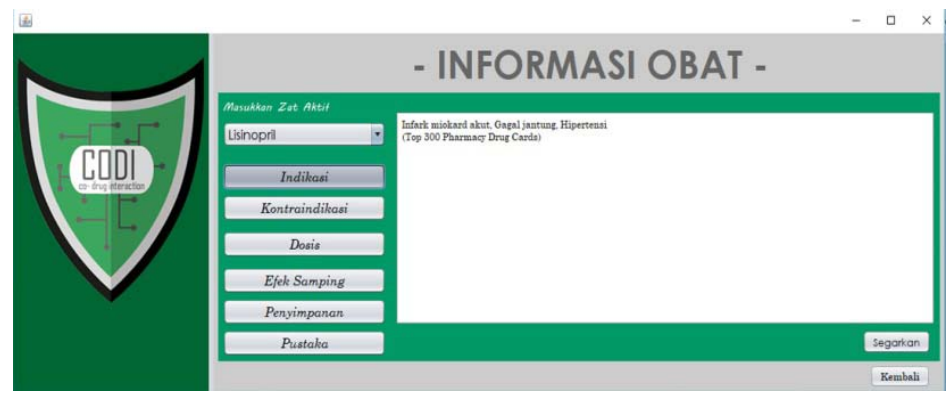

Fig. 7: Input on the drug information feature and result information 


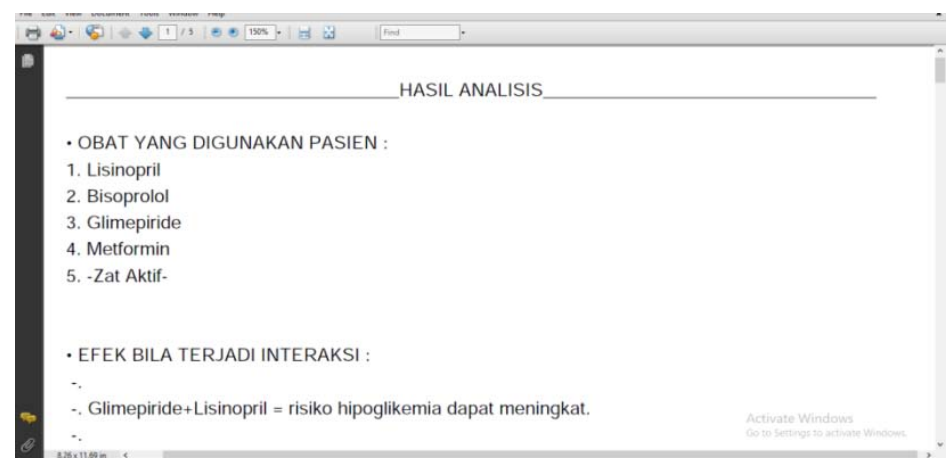

Fig. 8: Output results in the form of a PDF file

\section{Evaluation of CODI (Co-drug interaction) software}

At this stage, as many as 30 groups of active substances for hypertension and diabetes mellitus were made; the output is in the form of a PDF file as shown in fig. 8 below.

To find out that the results of the analysis of the suitability analysis feature and recommendation features when an interaction occurs is valid, the results are compared with the interaction data and recommendations for each active substance with each other active substance based on data from the e-book Drug Interaction Facts (2009) [8].

In the first group, there are active substances used, namely lisinopril, bisoprolol, glimepiride and metformin; the second group has active substances used, namely candesartan, amlodipine, and metformin, and the third group of active substances used are acarbose, metformin, nadolol, nifedipine, and valsartan., where each active substance used is compared with other active substances based on existing data on the Drug Interaction Facts in order to know the interactions and recommendations if there is an interaction of all active substances used.

After comparing the results of the CODI (Co-Drug Interaction) Software output on existing features with drug interaction data and recommendations from Drug Interaction Facts, it can be seen that the results of the analysis in the first, second, and third groups are in accordance with the interaction data and their recommendations. The first group is glimepiride, which interacts with lisinopril, the second group is that there is no interaction, and the third group is metformin which interacts with acarbose and nadolol which interacts with nifedipine. According to Tatro (2009) glimepiride+lisinopril provides an interaction, namely the risk of hypoglycemia can be increased and its recommendations namely carefully observing the symptoms of hypoglycemia when starting ACE Inhibitor therapy in patients receiving Sulfonylurea therapy $[8,9]$. Nadolol+nifedipine provides an interaction; namely, the pharmacological effects of both drugs can be strengthened and the recommendation is to carefully monitor the cardiac function of patients with risk of side effects [10]. The largest cardiovascular and metforim+acarbose provide the interaction ie the onset of metformin effects may be delayed after the initial dose and the recommendation is that based on available data no special precautions are required [11].

In evaluating the suitability of the button with the command form, there were no errors found. Each button describes its commands well.

\section{CONCLUSION}

Based on the research that has been done, it can be concluded that The design of the CODI (Co-Drug Interaction) software algorithm is in accordance with the output of the software in the form of a list of active substances used, along with its interactions and recommendations based on the active substances selected. The results of reliability testing by designing 30 groups of active substances based on 2 diseases, namely hypertension and diabetes mellitus, are in accordance with the comparison of interaction data and recommendations based on data from the e-book Drug Interaction Facts so that it can be stated that the results of CODI (CoDrug Interaction) analysis is valid. Likewise, in testing efficiency by looking at the suitability of the button and the shape of the command, it can be stated that it is appropriate to use.

\section{ACKNOWLEDGMENT}

The author gratefully acknowledges the Library of Faculty of Mathematics and Natural Sciences Tadulako University, who have provided literature for this research.

\section{FUNDING}

No competing financial interests exist.

\section{AUTHORS CONTRIBUTIONS}

Muhamad Rinaldhi Tandah and Yusriadi arranged the algorithm and provided the database, Alwiyah Mukaddas and Khusnul Diana pictured the interface until the application met appropriate and friendly look, Ahmad Anggara Sadewa made the brand's logo and translated the database into the programming language. Writing the english version of the manuscript did by Muhamad Rinaldhi Tandah.

\section{CONFLICT OF INTERESTS}

The authors have no conflict of interest to declare.

\section{REFERENCES}

1. Athira JI, Chaithanya KT, Joffey SJ, Kavitha SP, Sambath KR. A prospective study of drug-drug interactions and adverse drug reactions among stroke patients in a tertiary care hospital. Asian J Pharm Clin Res 2016;9:100-4.

2. Ubaka CM, Ekwe C, Isah A, Mukhtar AB, Ukwe CV. Students' knowledge and risk of committing medication errors in two schools of pharmacy in Nigeria. Asian J Pharm Clin Res 2020;13:57-2.

3. Prajwal AT, Muddukrishna BS, Vasantharaju SG. Pharma 4.0impact of the internet of things on health care. Int J Appl Pharm 2020;12:64-9.

4. Nurlaelah I, Mukaddas A, Faustine I. Kajian interaksi obat pada pengobatan diabetes melitus dengan hipertensi di Instalasi Rawat Jalan RSUD Undata periode Maret-Juni Tahun 2014. Galen J Pharm 2015;1:35-41.

5. Mahamudu YS, Citraningtyas G. Kajian potensi interaksi obat antihipertensi pada pasien hipertensi primer di Instalasi Rawat Jalan RSUD Luwuk periode Januari-Maret 2016. Pharmacon J Ilm Farm 2017;6:1-9.

6. Handayani K. Analisis potensi interaksi obat diabetes melitus pada resep obat pasien rawat jalan di RSAL Dr. Mintohardjo. Jakarta: UIN Repository; 2015.

7. Kadir A. Buku pertama belajar pemrograman Java untuk pemula. first ed. Yogyakarta: PT. Buku Seru; 2014.

8. Tatro DS, Olin BR. Drug interaction facts: facts and comparisons. St. Louis, MO: J. B. Lippincott Co; 1992.

9. Sari SP, Darajat AF, Nursanti B. Drug interactions among patients with hypertension taking angiotensin converting 
enzyme inhibitors in an Indonesian hospital. Int J Appl Pharm 2018;10(Special Issue 1):138-41.

10. Patil JP, Patil SV, Bhore P. Prescription analysis of hypertensive patients and awareness among physician regarding antihypertensive drug. Int J Curr Pharm Sci 2020;12:124-8.
11. Londhe SP, Joseph AB, John JO, Philip KI, Philip LI. To identify, evaluate, and analyze possible drug-drug interactions in patients diagnosed as type 2 diabetes mellitus with hypertension in a tertiary care teaching hospital. Asian J Pharm Clin Res 2015;8:169-74. 